\title{
Magnetic Properties and Giant Magnetoimpedance in Amorphous and Nanocrystalline Microwires
}

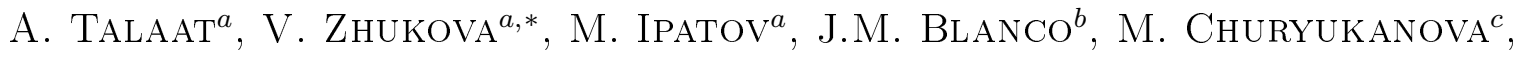 \\ S. Kaloshikin ${ }^{c}$, E. Kostitcyna $^{c}$, E. Shuvaeva ${ }^{c}$, L. GonZAlez-Legarreta $^{d}$, \\ B. HERNANDO ${ }^{d}$ AND A. ZHUKOV ${ }^{a, e}$
}

${ }^{a}$ Dpto Física de Materiales, Facultad de Química, UPV/EHU, 1072, 20080, San Sebastian, Spain

${ }^{b}$ Dpto de Física Aplicada, EUPDS, UPV/EHU, 20018, San Sebastian, Spain

${ }^{c}$ National University of Science and Technology "MISIS", Moscow, 119049, Russia

${ }^{d}$ Dpto de Física, Universidad de Oviedo, Calvo Sotelo s/n, 33007 Oviedo, Spain

eIKERBASQUE, Basque Foundation for Science, Bilbao, Spain

\begin{abstract}
We studied magnetic properties and GMI effect of Finemet-type FeCuNbSiB microwires. We observed that GMI effect and magnetic softness of microwires produced by the Taylor-Ulitovski technique, can be tailored by either controlling magnetoelastic anisotropy of as-prepared FeCuNbSiB microwires or controlling their structure by heat treatment or changing the fabrication conditions. GMI effect has been observed in as-prepared Fe-rich microwires with nanocrystalline structure.
\end{abstract}

DOI: 10.12693/APhysPolA.126.146

PACS: 75.50.Tt, 75.30.Gw, 75.50.-y

\section{Introduction}

Studies of glass coated ferromagnetic microwires (typically of 5-30 $\mu \mathrm{m}$ in diameter) have attracted growing attention in the last few years, owing to their outstanding soft magnetic properties (magnetic bistability, enhanced magnetic softness, GMI effect) [1, 2]. Optimization of soft magnetic properties and GMI effect of amorphous glass coated microwires is possible by choosing the appropriate chemical composition of metallic nucleus and adequate annealing conditions [1]. In some cases, nanocrystallization allows achieving good magnetic softness and enhanced GMI effect. Such soft magnetic character is related with vanishing magnetocrystalline anisotropy and the very small magnetostriction value, when the grain size approaches $10 \mathrm{~nm}$ [3].

In this paper we studied correlation of magnetic properties, GMI effect and structure of Finemet-type microwires.

\section{Experimental details}

We studied Finemet-type $\mathrm{Fe}_{70.8} \mathrm{Cu}_{1} \mathrm{Nb}_{3.1} \mathrm{Si}_{14.5} \mathrm{~B}_{10.6}$, $\mathrm{Fe}_{71.8} \mathrm{Cu}_{1} \mathrm{Nb}_{3.1} \mathrm{Si}_{15} \mathrm{~B}_{9.1}$, and $\mathrm{Fe}_{73.8} \mathrm{Cu}_{1} \mathrm{Nb}_{3.1} \mathrm{Si}_{13} \mathrm{~B}_{9.1}$ glass-coated microwires with different metallic nucleus diameter, $d$, and total microwire diameter, $D$, produced by Taylor-Ulitovsky method [1-3]. The strength of internal stresses is determined by ratio $\rho=d / D$ [4]. Controllable change of the $\rho$-ratio allowed us to tailor the residual stresses. Hysteresis loops have been obtained by flux-metric method, as described elsewhere $[1,2]$.

We measured magnetic field dependences of the GMI ratio, $\Delta Z / Z$, for as-prepared samples and samples after

\footnotetext{
*corresponding author; e-mail: valentina.zhukova@ehu.es
}

the heat treatments, at frequencies, $f$, up to $2 \mathrm{GHz}$, using vector network analyzer as described elsewhere [1].

Structure and phase composition have been checked using a BRUKER (D8 Advance) X-ray diffractometer with $\mathrm{Cu} \mathrm{K}_{\alpha}(\lambda=1.54 \AA)$ radiation.

\section{Results and discussion}

All as-prepared and even annealed Finemet-type microwires (with annealing temperature, $\mathrm{T}_{a n n}$, below first crystallization process), present squared hysteresis loops similar to Fe-rich amorphous microwires. (Fig. 1). As expected from previous studies of Fe-rich amorphous microwires [1], the coercivity, $\mathrm{H}_{C}$, of as-prepared Finemettype microwires depends on ratio $\rho=d / D$ (Fig. 2).

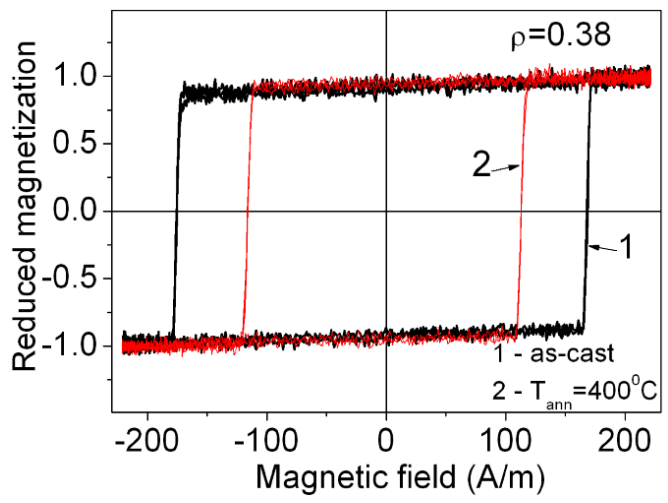

Fig. 1. Hysteresis loops of as-prepared and annealed $\mathrm{Fe}_{70.8} \mathrm{Cu}_{1} \mathrm{Nb}_{3.1} \mathrm{Si}_{14.5} \mathrm{~B}_{10.6}$ microwires with $\rho=d / D=$ 0.38 .

The dependence of coercivity of $\mathrm{Fe}_{71.8} \mathrm{Cu}_{1} \mathrm{Nb}_{3.1} \mathrm{Si}_{15} \mathrm{~B}_{9.1}$ microwires on the annealing temperature, shown in Fig. 3a, presents considerable 


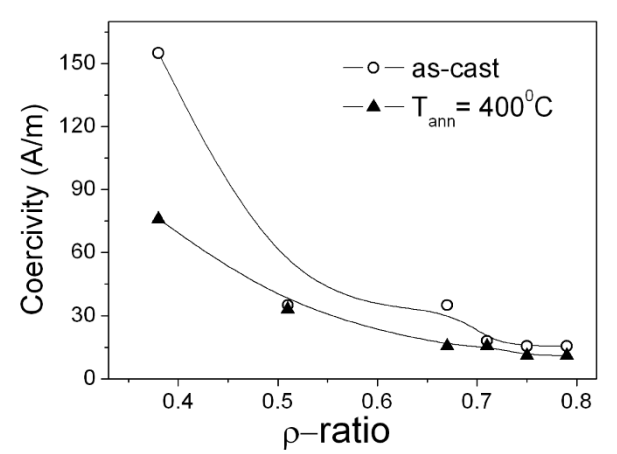

Fig. 2. Coercivity dependence on the $\rho$-ratio for asprepared $\mathrm{Fe}_{70.8} \mathrm{Cu}_{1} \mathrm{Nb}_{3.1} \mathrm{Si}_{14.5} \mathrm{~B}_{10.6}$ microwires.
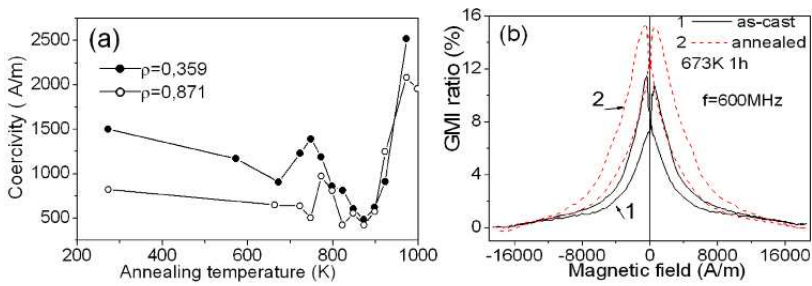

Fig. 3. Annealing temperature dependence of coercivity of $\mathrm{Fe}_{71.8} \mathrm{Cu}_{1} \mathrm{Nb}_{3.1} \mathrm{Si}_{15} \mathrm{~B}_{9.1}$ microwires with different $\rho$-ratios (a) and $\Delta Z / Z(H)$ dependences of $\mathrm{Fe}_{73.8} \mathrm{Cu}_{1} \mathrm{Nb}_{3.1} \mathrm{Si}_{13} \mathrm{~B}_{9.1}$ microwires $(d=20.3 \mu \mathrm{m}, \rho=$ $0.71)$, measured in as-prepared and annealed at $673 \mathrm{~K}$ samples (b).

magnetic softening at annealing temperatures, $\mathrm{T}_{a n n}$, between 800 and $900 \mathrm{~K}$, as was previously observed in other Finemet-type materials and Finemet-type microwires $[1$, $3,4]$. The increase of the GMI effect (Fig. 3b), observed after annealing of $\mathrm{Fe}_{73.8} \mathrm{Cu}_{1} \mathrm{Nb}_{3.1} \mathrm{Si}_{13} \mathrm{~B}_{9.1}$ microwires, must be related with stress relaxation (confirmed by the decrease of coercivity after annealing, shown in Fig 3a).
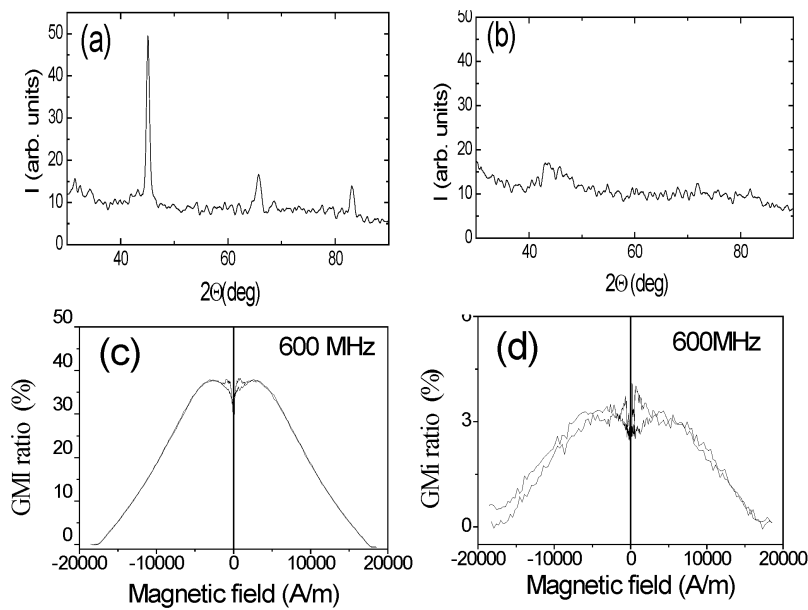

Fig. 4. X-ray diffraction patterns of as-prepared $\mathrm{Fe}_{73.8} \mathrm{Cu}_{1} \mathrm{Nb}_{3.1} \mathrm{Si}_{13} \mathrm{~B}_{9.1} \quad(\rho=0.6) \quad(\mathrm{a})$ and $\mathrm{Fe}_{70.8} \mathrm{Cu}_{1} \mathrm{Nb}_{3.1} \mathrm{Si}_{14.5} \mathrm{~B}_{10.6}(\rho=0.49)$ (b) microwires and GMI effect in the same samples (c, d).
Particularly in the as-prepared $\mathrm{Fe}_{73.8} \mathrm{Cu}_{1} \mathrm{Nb}_{3.1} \mathrm{Si}_{13} \mathrm{~B}_{9.1}$ microwires we observed existence of $\alpha$-Fe nanocrystallites with average grain size about $12 \mathrm{~nm}$ (Fig. 4a). The average grain size has been estimated from the width of the crystalline peak, using the Debye-Scherrer equation. For comparison the X-ray diffraction pattern of completely amorphous as-prepared $\mathrm{Fe}_{70.8} \mathrm{Cu}_{1} \mathrm{Nb}_{3.1} \mathrm{Si}_{14.5} \mathrm{~B}_{10.6}$ microwire is shown in Fig. 4b. In as-prepared $\mathrm{Fe}_{73.8} \mathrm{Cu}_{1} \mathrm{Nb}_{3.1} \mathrm{Si}_{13} \mathrm{~B}_{9.1}$ microwires we observed considerable GMI effect (up to $\Delta Z / Z \approx 35 \%$ at $f=600 \mathrm{MHz}$, see Fig. 4c). The observed considerable GMI effect in the as-prepared $\mathrm{Fe}_{73.8} \mathrm{Cu}_{1} \mathrm{Nb}_{3.1} \mathrm{Si}_{13} \mathrm{~B}_{9.1}$ microwires is much higher than that of $\mathrm{Fe}_{70.8} \mathrm{Cu}_{1} \mathrm{Nb}_{3.1} \mathrm{Si}_{14.5} \mathrm{~B}_{10.6}$. This difference must be attributed to amorphous structure of $\mathrm{Fe}_{70.8} \mathrm{Cu}_{1} \mathrm{Nb}_{3.1} \mathrm{Si}_{14.5} \mathrm{~B}_{10.6}$ and nanocrystalline structure, and consequently lower magnetostriction, of $\mathrm{Fe}_{73.8} \mathrm{Cu}_{1} \mathrm{Nb}_{3.1} \mathrm{Si}_{13} \mathrm{~B}_{9.1}$ microwires.

Consequently, although GMI effect in as-prepared amorphous Fe-rich microwires is rather small, in the as-prepared $\mathrm{Fe}_{73.8} \mathrm{Cu}_{1} \mathrm{Nb}_{3.1} \mathrm{Si}_{13} \mathrm{~B}_{9.1}$ with nanocrystalline structure we observed the enhanced GMI effect (Figs. 4c). Enhancement of the $\Delta Z / Z$ ratio in as-prepared nanocrystalline microwires and after their annealing might be related with magnetic softening of studied microwires after annealing, related with reduction of magnetostriction and relaxation of internal stress.

\section{Conclusions}

We observed magnetic softening and considerable GMI effect in Finemet-type $\mathrm{FeCuNbSiB}$ with nanocrystalline structure. Magnetoelastic anisotropy affects soft magnetic properties and the GMI effect of FeCuNbSiB microwires.

\section{Acknowledgments}

This work was supported by EU ERA-NET programme under project "SoMaMicSens" (MANUNET2010-Basque-3), by Spanish MICINN under project MAT2010-18914, by the Basque Government under Saiotek-12 MEMFOMAG project (S-PE12UN139) and by federal target program "Scientific and scientificpedagogical personnel of innovative Russia", state contract no 14.Ŕ18.21.0762. A. Zh. and V.Zh. wish to acknowledge support of the Basque Government under the Mobility Program (grants MV-2013-2-22 and MV2013-2-23). Technical and human support provided by SGIker (UPV/EHU, MICINN, GV/EJ, ERDF and ESF) is gratefully acknowledged.

\section{References}

[1] V. Zhukova, M. Ipatov, A. Zhukov, Sensors 9, 9216 (2009).

[2] D.C. Jiles, Acta Mater 51, 5907 (2003).

[3] C. Dudek, A.L. Adenot-Engelvin, F. Bertin, O. Acher, J Non-Cryst Solids 353, 925 (2007).

[4] H. Chiriac, T.-A. Ovari, A. Zhukov, J. Magn. Magn. Mater. 254-255, 469 (2003). 